Journal of Ancient Philosophy Vol. II 2008 Issue 2

\title{
Virtude e Felicidade em Aristóteles e Hobbes
}

\section{Yara Frateschi (Unicamp)}

The main target of this article is to show that to sustain the social contract as the origin of political power and civil society and to justify the necessity of absolute sovereignty, Hobbes has to oppose not only Aristotle's theory of zoon politikon but also his moral theory, particularly the doctrine of the mean.

É conhecido que a construção da filosofia política hobbesiana se faz a partir da crítica e substituição do princípio aristotélico do animal político. Ao recusar a natureza política dos homens, a intenção de Hobbes é estabelecer a origem do Estado pelo contrato e justificar a necessidade da soberania absoluta, que se torna condição necessária para a coexistência de indivíduos exclusivamente auto-interessados. O objetivo deste artigo é mostrar que, para que se concretize seu o projeto, Hobbes deverá não apenas recusar o zoon politikon de Aristóteles, mas também a noção de virtude como mediania e suas implicações maiores. Se a recusa da filosofia política de Aristóteles é necessária para que se estabeleça a origem do Estado pelo contrato, a recusa da sua filosofia moral é fundamental para que se justifique a manutenção do Estado absoluto bem como a sua função doutrinadora. Que os homens não são animais políticos e são incapazes de serem educados para a virtude (no sentido aristotélico) são teses solidárias, derivadas do mesmo princípio, a saber, o princípio do benefício próprio, segundo o qual os homens, por natureza e necessidade, buscam sempre e em todas as suas ações realizar o seu próprio bem, sendo todo o resto desejado no interesse desse fim. Este é o princípio que Hobbes mobiliza para recusar tanto a política quanto a ética de Aristóteles em nome da defesa permanente do leviatã. 
Journal of Ancient Philosophy Vol. II 2008 Issue 2

Trazer à luz os pontos centrais da crítica hobessiana (não enunciada explicitamente) ao tratado da virtude moral de Aristóteles contribui ainda para que se apreenda o ponto mais frágil das interpretações que atribuem a Hobbes uma moral independente da psicologia e anterior à política. É com esse objetivo que Taylor, para citar um expoente dessa linha interpretativa, aproxima Hobbes de Kant e defende haver, no primeiro, um imperativo moral determinado pela reta razão à semelhança do imperativo categórico kantiano ${ }^{1}$. Uma leitura detida da primeira parte das três obras políticas de Hobbes, dedicadas à filosofia moral, mostra a deficiência dessa leitura sem que seja preciso explorar as diferenças entre o autor do Leviatã e o autor da Fundamentação da metafísica dos costumes. Os argumentos que Hobbes mobiliza contra a moral aristotélica são suficientes para entender porque a sua "lei” moral opera num registro radicalmente distinto do imperativo categórico kantiano. Este texto pretende, então, indicar que as leituras que pretendem atribuir uma base moral à filosofia política de Hobbes dificilmente resistiriam aos argumentos que ele mesmo mobiliza contra Aristóteles.

À primeira vista há diversos pontos de contato entre a filosofia moral de Hobbes e de Aristóteles, especialmente no tocante ao modo de operação da razão prática e ao papel central desempenhado pelo desejo. No que diz respeito ao último aspecto, ambos reconhecem que os desejos fazem parte da natureza humana tanto quanto a razão e não vinculam a virtude com a falsa expectativa de uma vida livre de emoções ou paixões. Diferem, nesse sentido, dos estóicos que definem a paixão - em si mesma um pecado como ignorância e vício ${ }^{2}$. Em seu ideal de apatheia, o estoicismo faz do virtuoso um homem que, tendo se libertado inteiramente das paixões, atingiu a plena realização da

\footnotetext{
${ }^{1}$ A. E. Taylor, "The Ethical Doctrine of Hobbes”, in K. C. Brown (ed.), in Hobbes Studies, Cambridge, Mass., Harvard University Press, 1965, pp. 35-55, p. 37.
}

\footnotetext{
${ }^{2}$ De Finibus, III, IX, 32. Tratei mais demoradamente desse aspecto do estoicismo em contraste com Hobbes na minha tese de doutorado A Física da Política: Hobbes contra Aristóteles. USP. 2003.
} 
perfeição humana e pode, então, viver segundo o logos. Hobbes e Aristóteles, em contrapartida, sabem que não é possível condicionar a virtude e a boa conduta à ausência de emoções ou paixões porque a aphateia simplesmente não é para os humanos $^{3}$. Desejos são constitutivos da alma e são, em alguma medida, o motor da ação. Sem eles, qualquer homem seria inerte, sem vida, enfim, incapaz de ação. Em ambos os casos, portanto, não cabe à filosofia moral condenar os desejos como se fossem um mal em si, mas sim discriminá-los a fim de determinar em que medida, quando e por que eles (e quais deles) conduzem à boa ou à má conduta.

Em função do papel central que o desejo desempenha na filosofia moral aristotélica e também na hobbesiana devemos nos deter nesse aspecto, ainda que não demoradamente, a fim de destacar ao menos três pontos gerais de convergência. 1) Hobbes concorda inteiramente com Aristóteles acerca do móbil da ação: é o desejo, e não a razão, que põe fins aos homens, imprimi movimento e conduz à ação ${ }^{4}$. 2) Nos dois autores, a cadeia causal da ação segue esta ordem: o desejo põe o fim, o homem delibera e age. O desejo é o ponto de partida da deliberação, sendo o último passo da deliberação o ponto de partida do movimento que gera a ação. A razão, portanto, é responsável por determinar os meios para que se atinja fins postos pelo desejo. 3) Para ambos, o desejo se relaciona com uma emoção ou paixão ${ }^{5}$ que segue uma opinião, ou seja, a imaginação do prazer, do bem ou do benefício que poderão advir. Enquanto

${ }^{3}$ Como aponta Marco Zingano, não se deve temer o anacronismo aqui, pois “o próprio Aristóteles mencionou (sem, porém, os nomear) os que, já em sua época, definiam as virtudes como 'estados de impassibilidade - apatheias - e de quietude' (EN II 2 1104b24-25); e ele os menciona para imediatamente recusá-los" (ZINGANO, M. "Emoção, ação e felicidade em Aristóteles” in Estudos de Ética Antiga. São Paulo, Discurso Editorial, 2007, p. 144).

${ }^{4}$ Como mostra Marisa Lopes, diferentemente de Platão, para quem a "phronêsis é a forma de conhecimento mais elevada e o conhecimento que ela gera é razão suficiente para fazer um homem agir bem", Aristóteles entende que "ninguém age apenas em função do que sabe ser um bem (...) mas porque deseja agir segundo as razões da bondade da ação ou do fim que se realiza na ação". LOPES, M. A Relação entre virtude moral e phronêsis no livro VI da Ética Nicomaquéia. Dissertação de Mestrado, FFLCH, USP, 2000, p. 8-9.

${ }^{5}$ Aristóteles assim se refere à emoção: "Entendo por emoções apetite, cólera, medo, arrojo, inveja, alegria, amizade, ódio, anelo, emulação, piedade, em geral tudo a que se segue prazer ou dor (EN II 4 1105b21). Hobbes denomina paixão o que em Aristóteles é emoção. Ver Leviatã, cap. VI, os exemplos de paixões são os mesmos, com algumas omissões. 
motor da ação, o desejo segue uma emoção ou paixão que é, por sua vez, resultado de uma alteração no sujeito que tem origem numa opinião, imaginação ou juízo.

Acompanhando Aristóteles no que diz respeito à importância do desejo na determinação da ação, Hobbes também traz o prazer para o centro da discussão moral. Numa passagem da Ética Nicomaquéia à qual Hobbes daria seu completo assentimento, Aristóteles diz que desde a infância "somos todos criados com ele [o prazer]: por isso nos é difícil desvencilhar desta afecção entranhada na vida” (EN II 2 1105ª). De seu lado, Hobbes afirma que o prazer é a aparência ou sensação de bem (Leviatã VI) e tudo o que os homens fazem é em nome do que consideram um bem. Ambos, portanto, reconhecem que a filosofia moral deve levar a sério a importância do prazer dado o seu papel na determinação da ação. No entanto, a convergência entre os dois autores é muito superficial, a começar daqui. Se Hobbes concorda com Aristóteles quanto à centralidade do desejo e do prazer na determinação da ação, nem por isso concorda com o desdobramento ético dessa constatação. Para Aristóteles, é marca distintiva do homem virtuoso não apenas agir virtuosamente, mas sentir prazer ao praticar ações nobres. Essa identificação do virtuoso com aquele que sente prazer em bem agir está ausente da filosofia hobbesiana, que não vincula a virtude com o prazer de bem agir, mas apenas com o bem agir, mesmo reconhecendo que dores e prazeres, assim como os medos e as esperanças (as paixões de um modo geral) são determinantes da ação. As razões dessa dissonância nos levam ao coração da divergência de Hobbes com Aristóteles no domínio da filosofia prática e revelam a alteração que Hobbes precisa fazer na filosofia aristotélica para justificar a necessidade da soberania absoluta. Para justificar a permanência do leviatã ele precisa recusar a possibilidade da educação do prazer, do desejo ou da emoção e, ao mesmo tempo, enfraquecer o papel da razão e da deliberação na determinação da ação. O caráter repressivo do Estado é justificado na medida em que compensa a falência do projeto aristotélico de educação para a virtude.

Para que possamos acompanhar a crítica que Hobbes faz à filosofia moral de Aristóteles deveremos reter alguns pontos da Ética Nicomaquéia que, como veremos, serão sucessivamente retomados e recusados na primeira parte do Elemens of Law, do Do Cidadão e do Leviatã. É digno de nota o fato de que Hobbes questiona passo a 
Journal of Ancient Philosophy Vol. II 2008 Issue 2

passo o tratado da virtude moral de Aristóteles sem, contudo, fazer qualquer menção direta a Aristóteles e tampouco aos seus tratados de ética. Mas a ausência de referencia explícita não é capaz de esconder o oponente.

\section{1) Virtude e felicidade, segundo Aristóteles ${ }^{6}$}

“Dado que a felicidade é certa atividade da alma segundo perfeita virtude, deve-se investigar a virtude, pois assim, presumivelmente, teremos também uma melhor visão da felicidade. O verdadeiro estadista parece igualmente ocupar-se sobretudo dela, pois pretende tornar os cidadãos bons e obedientes às leis (...).” (EN I 13 11025-10).

A passagem supracitada da Ética Nicomaquéia aponta para uma relação entre a ética e a política introduzindo o tema da educação para virtude. Vejamos brevemente como se relacionam felicidade, virtude e educação para a virtude nos livros I e II da Ética para, em seguida, retomarmos a crítica de Hobbes. Na Ética, precede a apresentação do Sumo Bem a afirmação de que toda ação, assim como toda escolha, tem em mira um bem qualquer, sendo o bem aquilo a que todas as coisas tendem. Há dois tipos de fins, que consistem nas próprias atividades (fins que desejamos por si mesmos) ou nos produtos das atividades (fins que desejamos como meios para uma outra coisa). O Sumo Bem, por sua vez, é um fim que desejamos por si mesmo, e tudo o mais é desejado no seu interesse. Segundo Aristóteles, ele coincide com a felicidade, que é a mais desejável de todas as coisas e, portanto, não pode ser enumerada como um bem entre outros. Ora, uma vez que a função do homem é uma atividade da alma conforme a razão (EN I, 7, 1098 33-8), a felicidade não se reduz à obtenção de honras ou de prazeres, mas consiste numa certa atividade da alma conforme à virtude, o que está em harmonia com a afirmação de que os bens da alma são bens em sentido mais elevado e completo do que os bens externos e os bens do corpo (EN I, 7, 1098 ${ }^{\mathrm{b}} 13-19$ ). Sabemos ainda que, para Aristóteles, a realização da felicidade não se dá apenas no âmbito individual. Por ser o bem supremo para os homens e tratar-se de algo auto-suficiente,

\footnotetext{
${ }^{6}$ Reproduzo nessa seção parte do texto de minha tese doutorado. CF. FRATESCHI. Y. A Física da política: Hobbes contra Aristóteles, pp. 133-140.
} 
ela deve ser buscada no âmbito da polis, já que o termo “auto-suficiente” é empregado “não com referência a um homem sozinho, vivendo uma vida de isolamento, mas também aos seus pais, filhos e esposa e aos seus amigos e concidadãos em geral” (EN I, 7, 1097 8 -11) visto que o homem é, por natureza, um animal político. Ademais, sendo a virtude moral produzida pelo hábito (EN II, 1, $1103^{\mathrm{a}} 17$ ) e sendo a prática da virtude algo que diz respeito também às nossas ações para com os outros (V, 1, 1129 $9^{\mathrm{b}} 30$-33), ela deve ser estimulada e efetivada na vida (política) da cidade.

Educação para a virtude. A função principal da política é, pois, produzir um certo caráter nos cidadãos a fim de torná-los virtuosos e capazes de ações nobres (EN I, 9, 1099 30 -31). Daí que seja a política a ciência arquitetônica do domínio prático, à qual a ética se subordina: pertence a ela o estudo do Sumo Bem para os homens e o exame da virtude (EN I, 13, 1102 11 -15). Com a função de educar os cidadãos para a virtude, o homem político deve conhecer de certo modo a alma humana para que seja capaz de tornar os cidadãos bons por meio dos hábitos. E, para tanto, sem que seja necessária uma precisão maior do que esta, ele deve saber que a alma tem uma parte racional e outra privada de razão, sendo a primeira subdividida em parte científica ou pensamento especulativo (a que contempla as coisas cujas causas são invariáveis) e parte calculadora ou pensamento prático (a que contempla as coisas variáveis). A alma não racional, por sua vez, subdivide-se em parte vegetativa, que é comum a todas as espécies e é causa da nutrição e do crescimento, e parte desiderativa, locus dos desejos e dos apetites. Embora a parte vegetativa e a parte desiderativa sejam espécies de um mesmo gênero, o não racional - isto é, o que não tem razão por si mesmo -, o elemento desiderativo pode adquirir alguma racionalidade quando é conforme ao princípio racional.

Importa reter aqui que o desejo humano pode ser aperfeiçoado pela razão, o que garante, em princípio, a possibilidade da racionalidade de todas as nossas ações, o que depende, por sua vez, da educação para a virtude por meio da prática habitual de ações virtuosas. Para que seja frutífera, tal educação deve incidir sobre os prazeres e as dores, já que estes têm efeito determinante sobre as ações: “por causa do prazer cometemos atos vis, por cauda da dor nos abstemos de ações belas” (EN II, 3, 1104b10-11). Aristóteles defende que a educação certa deve começar na infância a fim de 
Journal of Ancient Philosophy Vol. II 2008 Issue 2

aprendermos a nos deleitar e a sofrer com as coisas que devem causar deleite e sofrimento. Essa educação se faz necessária não apenas porque há uma relação de determinação entre desejo e ação, mas também porque é marca distintiva do homem virtuoso não apenas agir virtuosamente, mas, como vimos, sentir prazer ao praticar ações nobres, justas, virtuosas. Para ele, as ações conformes à virtude são prazerosas por si mesmas, de tal modo que na sua pessoa não há conflito entre os desejos que tem e os que deveria ter, ou ainda entre os desejos que tem e as ações que deveria praticar. A proposta de Aristóteles não é educar para que se aprenda a agir de maneira “correta”, ainda que os nossos desejos nos empurrem para o lado oposto (tal é a moralidade cristã), mas sim educar os desejos para que sejam conformes à conduta virtuosa.

Mediania. Para que a escolha humana seja acertada e conduza a uma ação virtuosa, o desejo deve perseguir o que afirma o princípio racional. Daí Aristóteles afirmar que a escolha deliberada é um raciocínio desiderativo ou um desejo raciocinado (EN VI, 2, 1139 4-5) ${ }^{7}$. Na origem dessa afirmação, há duas constatações: 1) o homem é um misto de razão e desejo, ou, por outra, a sua alma se divide em partes distintas, mas inseparáveis - a racional e a não racional; 2) em certo sentido, há um elemento na parte não racional da alma que participa da razão: o elemento desiderativo, que pode obedecer à razão (EN I 13 1102b31). Isso nos remete ao último ponto que devemos abordar nessa apresentação dos temas do tratado da virtude moral recuperados e criticados por Hobbes. A virtude moral de Aristóteles não é uma emoção nem uma faculdade, mas uma disposição da alma que torna o homem bom e o faz desempenhar bem a sua função, a qual consiste numa certa atividade conforme ao princípio racional (II, 6, $\left.1106^{\mathrm{a}} 23-24\right)$ e para desempenhá-la bem, isto é, com excelência, é preciso ter em mira o meio termo: “A virtude é, portanto, uma disposição de escolher por deliberação, consistindo em uma mediedade relativa a nós, disposição delimitada pela razão, isto é, como delimitaria o prudente” (EN II 6 1106b36-1107ª). O meio termo situa-se entre o excesso e a falta e pode ser encontrado tanto no que diz respeito às paixões quanto às

\footnotetext{
${ }^{7}$ Marco Zingano traduz essa passagem do seguinte modo: a escolha deliberada é "o intelecto desiderativo ou o desejo reflexionante”. ARISTÓTELES. Ethica Nicomachea I 13 - III 8. Tratado da virtude moral. Tradução, notas e comentários de Marco Zingano. São Paulo, Ed. Odysseus. 2008.
} 
ações. No primeiro caso, realiza-se quando, por exemplo, o medo, a confiança, a ira, o desejo, o prazer e a dor são sentidos sem excesso ou escassez, o que seria um mal. É marca da virtude moral que sejam sentidos no tempo e na ocasião corretos, em relação à pessoa certa, pelo propósito certo e da maneira correta (EN II, 6, 1106 20 -23). No que diz respeito às ações, o meio termo também pode e deve ser realizado. A virtude é, pois, uma disposição de caráter que determina a escolha de ações e emoções e que consiste, essencialmente, na observância do meio termo relativamente a nós, o qual é, por sua vez, determinado pelo princípio racional. Não que seja fácil alcançá-la, pois tendemos por natureza mais às ações e às paixões contrárias ao meio termo, de onde se segue que somos mais facilmente levados à intemperança do que à virtude (EN II, 8, 1109ª11-19). Mas embora não seja empresa fácil, também não é impossível encontrar o meio termo e, ao menos em princípio, todos os seres racionais são capazes de fazê-lo e devem ser educados para tanto.

Na primeira parte das suas obras políticas Hobbes questiona ponto por ponto os temas acima destacados do tratado da virtude moral de Aristóteles, ainda que sem menção explícita ao oponente. Mais do que isso, ele empreende uma re-significação dos termos centrais daquele tratado (tais como felicidade, virtude e deliberação) pela qual se torna capaz de manter o léxico da filosofia moral tradicional, mas invertendo completamente o seu significado. Como “toda ciência começa por definições”, diz Hobbes, (De Homine XIII), alterar as definições da filosofia moral tradicional é condição necessária da alteração das suas conclusões. E assim, redefinindo corretamente os termos - que são o ponto de partida de qualquer investigação científica - “o verdadeiro filósofo moral” será capaz de demonstrar que a medida do bem e do mal, assim como da virtude e do vício, é dada pela lei de cada Estado e que, portanto, a conduta virtuosa não repousa, como queria Aristóteles, numa certa mediania entre dois extremos, mas corresponde à conduta em conformidade com o estabelecimento e manutenção da paz, ou seja, à conduta obediente (Do Cidadão III, 32). Vejamos.

\section{2) Virtude e felicidade, segundo Hobbes}


Vimos que Aristóteles associa a felicidade a uma atividade (certa atividade da alma segundo perfeita virtude), trata-se agora de mostrar como Hobbes altera aquela definição:

“O sucesso contínuo na obtenção daquelas coisas que de tempos em tempos os homens desejam, quer dizer, o prosperar constante, é aquilo a que os homens chamam felicidade; refiro-me à felicidade nesta vida. Pois não existe uma perpétua tranqüilidade de espírito enquanto aqui vivemos porque a própria vida não passa de movimento e jamais pode deixar de haver desejo, ou medo, tal como não pode deixar de haver sensação.” (Leviatã VI)

Para chegar à definição de felicidade como sucesso contínuo na obtenção dos objetos do desejo, Hobbes precisa desmentir a concepção teleológica de natureza sustentada pela tradição aristotélica e colocar, em seu lugar, uma teoria geral do movimento que recusa a causalidade final e admite apenas a causalidade eficiente ${ }^{8}$. Interessa aqui precisamente a conclusão que ele extrai dessa substituição no tocante à teoria da ação: ao eliminar a causa final, ele elimina também a idéia de Sumo Bem e, com isso, condena os homens a uma busca incessante de fins sempre provisórios. Para tanto, ele precisa recusar a distinção feita por Aristóteles, no início da Ética Nicomaqueia, entre fins que são atividades e fins que são produtos distintos das atividades, distinção necessária para a identificação da felicidade com uma atividade. O argumento de Hobbes é o seguinte: porque nunca deixamos de desejar e o desejo sempre pressupõe um fim mais longínquo (a obtenção de algo que não temos no presente), a felicidade não é uma atividade e tampouco é fim último ou bem supremo, mas apenas o sucesso contínuo da obtenção dos objetos do desejo ${ }^{9}$. Com isso Hobbes concluirá que a felicidade, tal como definida por Aristóteles, é mera utopia:

“Quanto a um fim último, no qual os filósofos antigos situaram a felicidade e muito discutiram sobre o caminho para atingi-la, não há semelhante

\footnotetext{
${ }^{8}$ Tratei mais demoradamente dessa questão na minha tese de doutorado A Física da Política: Hobbes contra Aristóteles, cap. 2.

9 Tratei mais detidamente dessa questão em "Filosofia da Natureza e Filosofia Moral em Hobbes” in Cadernos de História e Filosofia da Ciência, série 3, v. 15, n. 1 (jan.-jun. 2005).
} 
Journal of Ancient Philosophy Vol. II 2008 Issue 2

coisa neste mundo, nem caminho para ela, exceto em termos de Utopia; pois enquanto vivermos teremos desejos, e o desejo sempre pressupõe um fim mais longínquo” (Elements of Law I, VII, 6).

O fato de o desejo localizar-se necessariamente num objeto ausente (e dos fins serem sempre provisórios) elimina a possibilidade da identificação da felicidade com um modo de agir e introduz, inevitavelmente, uma lógica de resultados: tudo o que os homens fazem é em nome da aquisição de algo que julgam um bem para si próprios. Trata-se de um cálculo de utilidade condizente com o princípio que orienta a construção de todo o pensamento moral e político de Hobbes: o princípio do benefício próprio, segundo o qual a natureza humana conduz, em primeiro lugar, à procura do que cada um considera bom para si mesmo, sendo todo o resto desejado no interesse desse fim. No limite, todas as ações, coisas e pessoas são tratadas pelo indivíduo como meios, isto é, como instrumentos para a sua preservação e satisfação, de modo que o valor das ações, coisas e pessoas deriva do fato dos indivíduos as julgarem úteis para esse fim: “o valor de um homem, tal como o de todas as outras coisas, é seu preço; isto é, tanto quanto seria dado pelo uso de seu poder. Portanto, não absoluto, mas algo que depende da necessidade e julgamento de outrem” (Leviatã X). Segue-se que todos os valores são acidentais e relativos e que, portanto, não há a possibilidade de um acordo natural em torno das noções de bem e mal, que são estritamente individuais e incomunicáveis. Eis porque a felicidade deixa de ser um modo de agir e se torna o sucesso contínuo na satisfação dos desejos e, ao mesmo tempo, deixa de ser algo a ser procurado no âmbito na polis para se tornar apenas satisfação individual.

Em conformidade com o princípio do benefício próprio, Hobbes altera profundamente a natureza das ações virtuosas, que são boas porque consistem "em meios para uma vida pacífica, sociável e confortável” e não porque derivam de uma “mediocridade das paixões” (Leviatã XVI; Do Cidadão III, 32). Isso significa que as ações são boas instrumentalmente: as virtudes morais são "os meios da paz”. Ocorre que ainda que Hobbes afirme que a razão nos dá a conhecer as virtudes (a justiça, a gratidão, a modéstia, a equidade, a misericórdia), as leis de natureza não são propriamente leis, mas teoremas da razão relativos ao que contribui à paz e à defesa de 
Journal of Ancient Philosophy Vol. II 2008 Issue 2

cada um, ou seja, incapazes de obrigar ou impor a sua observância. Como a razão não tem esse poder de mando e a lei "é a palavra daquele que tem o direito de comandar os outros” ((Leviatã XV), não há nenhuma norma fora da sociedade civil, tampouco a norma da virtude e do vício. Com isso Hobbes defende que a virtude moral requer a vida política, mas não porque na cidade é possível disciplinar o caráter dos cidadãos (como poderia afirmar Aristóteles), mas porque a norma da virtude e do vício - a regra do bem e do mal - "não pode ser outra que não a lei de cada Estado” (De Homine, XIII, 9).

Com a intenção de defender que há uma teoria moral em Hobbes independente da sua psicologia e anterior à política, algumas leituras da filosofia hobbesiana - tais como as de Taylor e Warrender - precisam negligenciar a afirmação de que a regra do bem e do mal é a lei civil, ou seja, precisam recusar a conclusão principal da filosofia moral de Hobbes. Em linhas gerais a tese Taylor-Warrender defende que a moral hobbesiana não é uma moral meramente prudencial, isto é, uma moral que se construiria a partir do princípio do interesse, que é um princípio egoísta derivado da sua psicologia. Taylor entende que há em Hobbes (como em Kant!) um imperativo moral baseado na reta razão, sendo a moral anterior à política e a filosofia moral independente da psicologia. A exigência de separação entre moral e psicologia deve-se à tentativa de provar que a moral não é construída a partir do princípio do benefício próprio, pois encerra deveres que estão em conformidade com uma norma estabelecida pela razão independentemente do interesse. Daí Taylor encontrar semelhanças entre Hobbes e Kant no que diz respeito ao imperativo moral: haveria em Hobbes, como em Kant, uma diferença entre a ação conforme ao dever e ação por dever.

Não precisamos comparar a "lei” moral hobbesiana com o imperativo categórico kantiano para atestar a inadequação dessa leitura. Antes disso, basta mostrar, a partir do contraste com Aristóteles, que Hobbes não sustenta a idéia de uma moral universalista e independente da política justamente porque não aceita o que Taylor quer lhe atribuir, ou seja, a existência de valores que se sustentam em si mesmos independentemente do benefício que acarretam. A investigação da crítica feita por Hobbes dos temas centrais do tratado da virtude moral de Aristóteles nos poupa de uma aproximação indevida do filósofo inglês com o autor da Fundamentação da metafísica dos costumes, 
aproximação feita à custa de negligenciar o vínculo inegável entre a moral e a psicologia hobbesiana. Essas leituras, recusando a centralidade do princípio do benefício próprio, atribuem à razão hobbesiana uma função - a de estabelecer um imperativo moral - que ela não tem e não pode ter por ser uma faculdade meramente calculadora operando em indivíduos exclusivamente auto-interessados. Uma comparação com Aristóteles, o oponente principal de Hobbes (ao lado de Cícero) nas questões morais, dá conta de evidenciar onde está a falha dessas interpretações.

Quando Hobbes identifica as virtudes morais com o hábito (Do Cidadão III, 31; Elements of Law XVII, 14) de agir conforme os teoremas da razão ele até parece se aproximar de Aristóteles, que define a virtude como um hábito e um hábito delimitado pela razão. No entanto, a aproximação é enganosa porque Hobbes exclui o elemento definidor da virtude moral aristotélica, a saber, que a virtude consiste numa disposição de escolher por deliberação. As disposições, segundo Aristóteles, são estados da alma em função dos quais nos portamos bem ou mal com relação às emoções (EN II 4 1105b26). Nota-se que se Aristóteles trouxe as emoções para o centro do tratado sobre a virtude moral foi para dizer que elas precisam ser aperfeiçoadas e persuadidas de algum modo pela razão e que isso depende de uma educação capaz de gerar, por meio do hábito, disposições saudáveis do ponto de vista moral. Tais disposições são necessárias para que se atinja a mediania relativamente às emoções e ações. Como aponta Marco Zingano, “a virtude não é uma emoção, mas não ocorre sem emoções, dado que é uma disposição e toda disposição é um comportamento estável com relação às emoções” ${ }^{10}$. Em Hobbes as disposições (ingenia) são inclinações dos homens a determinados fins (De Corpore XIII, 1) e quando o hábito consolida disposições favoráveis à paz temos bons costumes (mores). No entanto, diferentemente de Aristóteles, ele não aposta na idéia de que o enraizamento de boas disposições é capaz de gerar uma estabilidade com relação às emoções (e esse é o cerne da sua filosofia moral). Essa estabilidade depende de um controle externo permanente e vem, sobretudo, do controle que o Estado exerce sobre as opiniões dos súditos mediante doutrinação, promessa de recompensa e ameaça de punição. Vemos, assim, que o ponto central da discordância é que as disposições do homem hobbesiano não gozam da mesma permanência que a disposição de caráter do

${ }^{10}$ ZINGANO, M. “Emoção, ação e felicidade em Aristóteles”. Estudos de Ética Antiga, p. 156. 
Journal of Ancient Philosophy Vol. II 2008 Issue 2

homem virtuoso de Aristóteles. E isso ocorre pelo menos por dois motivos: porque os desejos, em constante migração, são refratários ao controle da razão e porque a razão não é outra coisa senão uma faculdade de cálculo operando em indivíduos autointeressados. Esse dois fatores geram uma instabilidade interna que frustra a expectativa de uma educação para virtude e faz da felicidade aristotélica mera "utopia” (e que frustra, também, uma aproximação de Hobbes com Kant). Em Aristóteles, é a possibilidade de educação dos desejos que garante a fixidez de caráter do homem virtuoso. Quando Hobbes recusa essa possibilidade lhe resta identificar a virtude com a obediência civil: a norma vem de fora, não de dentro, ela é externa e não interna. Eis a razão pela qual a "lei” moral de Hobbes não antecede, em nenhum sentido, o imperativo categórico kantiano.

\section{3) Razão e desejo, segundo Hobbes}

Vimos inicialmente que Hobbes parece seguir Aristóteles ao colocar o desejo em posição privilegiada na determinação da ação. Também no que diz respeito à deliberação, Hobbes parece seguir à risca Aristóteles. No entanto, assim como no caso anterior (da centralidade do desejo), ele faz desaparecer completamente as exigências morais feitas pelo autor da Ética Nicomaquéia. Para ambos, na origem da deliberação sempre há um desejo por algo que parece ser um bem. Esse desejo funciona como um móbil, e o agente passa a se engajar num processo de deliberação que tem como fim a obtenção do alvo desejado: trata-se de um processo em que o raciocínio se volta para o alvo do querer. O desejo é o ponto de partida da deliberação, sendo o último passo da deliberação o ponto de partida do movimento que gera a ação. Ora, o trabalho da razão calculadora na deliberação hobbesiana parece coincidir com o da razão prática na deliberação aristotélica. No entanto, ainda que em ambos a razão calcule meios com vistas à obtenção do fim posto pelo desejo, uma investigação cuidadosa do papel da razão e da deliberação em Hobbes mostrará, novamente, que a aproximação é superficial porque este assimila a estrutura geral do processo deliberativo exposto na Ética, mas faz desaparecer a distinção entre boa deliberação e deliberação eficaz. Em suma, Hobbes abandona as exigências morais feitas por Aristóteles ao fazer da eficiência a marca distintiva do bom deliberador. 
Mesmo recusando que a razão estabeleça fins para os homens, Aristóteles não sustenta uma concepção meramente instrumental de racionalidade prática, ao menos no sentido hobbesiano. Se fosse exclusivamente uma faculdade de calcular meios eficientes, a razão seria responsável apenas pela eficácia da ação humana, e o bom deliberador seria o mais capaz em produzir o efeito desejado. Tratar-se-ia de um cálculo de resultados. Isso vale para Hobbes, mas não para Aristóteles. De acordo com Hobbes, delibera bem quem possui, graças à experiência ou à razão, a maior e mais segura capacidade de prever as conseqüências das coisas (Leviatã VI, 39). Nota-se que o tratamento que ele dá ao tema da boa deliberação está circunscrito à lógica do princípio do benefício próprio, de tal modo que o trabalho da razão é apenas o de encontrar meios eficazes para a preservação ou satisfação individual. Aristóteles, por sua vez, não considera que a boa deliberação seja apenas o cálculo mais eficaz: um homem mau pode deliberar com sucesso e nem por isso deliberar com retidão. Há aqui uma exigência da qual Hobbes se distancia completamente, a saber, que o procedimento implicado no processo de escolha vale mais do que o resultado da ação.

Para o autor da Ética Nicomaquéia, a virtude moral exige o hábito de escolher buscando o meio-termo e esse hábito conta mais do que o resultado do ato na hora de determinar o valor moral da ação. Isso não significa que as conseqüências não sejam importantes, mas sim que elas, sozinhas, não são capazes de conferir ao ato a qualidade de virtude. É uma exigência da ética aristotélica que a ação seja feita com base em razões morais. Daí a centralidade da escolha deliberada que "é acompanhada de pensamento e reflexão” (EN 1112ª 15 ) e capacita o agente a justificar a sua decisão por razões propriamente morais. Assim sendo, diz Aristóteles, “os atos são ditos justos e temperantes quando são tais quais os que faria o justo ou o temperante: é justo e temperante não quem os realiza, mas quem os realiza tal como os justos e temperantes os realizam” (II 3 1105b5-8) ${ }^{11}$. Para Hobbes, em contrapartida, uma ação é boa quando conduz à paz (ou, no caso da guerra, à preservação de si), ou seja, é o resultado que

\footnotetext{
${ }^{11}$ Como mostra Marco Zingano, o valor moral é mais propriamente apreendido não pelo que é feito, mas pela deliberação de como fazer e isso assegura ao domínio interno uma prerrogativa sobre o externo quanto à análise do valor moral da ação. Cf. "Emoção, ação e felicidade em Aristóteles” in Estudos de Ética Antiga p. 160.
} 
confere bondade à ação e não o procedimento ou as intenções do agente. Essa preeminência do resultado em relação ao modo de agir é a conseqüência mais marcante da crítica que Hobbes faz ao projeto moral e pedagógico de Aristóteles. A virtude não é mediedade (mediocridade, segundo Hobbes) porque o que importa é o resultado. Logo, a mais importante contribuição da filosofia moral não é dar os parâmetros do modo de agir verdadeiramente ético (que difere, pela sua motivação, da ação eficaz), mas demonstrar a necessidade da instituição do Estado. E do Estado absoluto.

O contraste com Aristóteles se faz sentir, sobretudo, na medida em que Hobbes reduz o papel da razão - e também da deliberação - na determinação do desejo e, consequentemente, da ação. De acordo com o filósofo inglês, o desejo consiste no sentimento de prazer ou desprazer em relação às coisas que percebemos, sentimentos esses que decorrem do movimento do objeto externo e que nos afeta, ajudando ou prejudicando o nosso movimento vital. Ademais, ele está em constante modificação, uma vez que a própria constituição do corpo humano se modifica constantemente, sendo impossível que as mesmas coisas provoquem sempre os mesmos apetites e as mesmas aversões. Ao afirmar que o desejo é determinado pela ação do objeto externo sobre o corpo, Hobbes descarta a possibilidade de que a razão venha a determiná-lo, ou ainda que haja internamente no homem a organização dos desejos sob o domínio da razão. Isso não significa que seja impossível um acordo entre desejo e razão. A feitura do pacto evidencia que eles podem convergir para a realização de uma ação, mas essa convergência se dá na medida em que a razão oferece os meios para que se alcance um fim posto pelo desejo e não na medida em que o desejo lhe obedece ${ }^{12}$. No que diz respeito à deliberação, vemos o seu papel ser reduzido pelo determinismo - no qual está ancorada a filosofia moral de Hobbes -, que o leva a recusar a liberdade da vontade e a defender que o homem, quando muito, é livre para mover-se na direção do objeto desejado, mas não é livre para querer isso ou aquilo. A vontade não se determina e não é

\footnotetext{
${ }^{12}$ O papel da razão (Do Cidadão III, 31) é fazer com que os homens entrem em acordo sobre um bem futuro. Embora eles não possam entrar em acordo quanto ao bem presente (porque medem o bem e o mal pelos seus desejos), eles podem sim concordar quanto a um bem futuro (as coisas futuras são percebidas apenas pela razão). A paz é um bem futuro que a razão indica enquanto tal.
} 
causa de si mesma, dependente que é do modo como reagimos internamente - e sobre o qual não deliberamos - à ação do mundo exterior. Isso significa que há causas necessárias que fazem com que os homens queiram o que querem ${ }^{13}$. Com isso Hobbes tira dos agentes morais aquela responsabilidade e a possibilidade de "autodeterminação” - ou seja, a capacidade de auto-governo garantida pela disciplina do caráter - que Aristóteles lhes atribui (e deles exige) ao dizer que o homem é princípio e gerador de suas escolhas como é de seus filhos (EN 1113b19). Segundo Hobbes, um indivíduo pode ser responsabilizado pela suas ações, mas não pode ser considerado responsável pelo seu querer porque o seu desejo e a sua vontade não estão sob seu poder.

Em suma, dois elementos profundamente contrastantes com Aristóteles impedem Hobbes de aceitar o projeto de educação para a virtude com vistas à formação do caráter: 1) segundo Hobbes, o princípio motor da ação não se encontra em nós, mas fora de nós, ou seja, nos objetos externos; 2) a razão intervém muito acanhadamente no processo decisório. Isso aponta para uma inversão de primeira grandeza: enquanto Aristóteles aposta na interioridade, ou seja, na possibilidade de que o sujeito venha a encontrar internamente a medida da ação, Hobbes, pode apostar apenas no controle externo. Se o princípio motor da ação não reside em nós e à razão está reservado o limitado papel da instrumentalidade eficaz, a medida e o controle da ação deverão ser sempre externos. Daí a impossibilidade da educação para a virtude e, finalmente, a necessidade da soberania absoluta. Há, em Hobbes, uma inflação da repressão justificada pela impossibilidade do “auto-governo” e pela falta de liberdade da vontade.

Vimos inicialmente que Hobbes mantém o vínculo estabelecido por Aristóteles entre o desejo e a opinião do prazer, do bem ou do benefício que poderão advir: o desejo segue uma emoção ou paixão que é, por sua vez, resultado de uma alteração no sujeito que tem origem numa opinião, imaginação ou juízo. Tome-se, por exemplo, a definição de medo e veremos que Hobbes assume, sem qualquer alteração, o texto da Retórica II 5, onde o medo é definido como uma dor ou perturbação que se segue à imaginação de

\footnotetext{
${ }^{13}$ Tratei do determinismo e da negação do livre-arbítrio no artigo "Liberdade e livre-arbítrio em Hobbes”, Cadernos de História e Filosofia da Ciência, Campinas, Série 3, vol. 17, 2007.
} 
Journal of Ancient Philosophy Vol. II 2008 Issue 2

um mal futuro ${ }^{14}$. No entanto, novamente ele extrai daí conclusões inteiramente diversas de Aristóteles. Para este é justamente o fato da emoção ter por base uma opinião ou um juízo que garante a possibilidade de que ela venha a ser aperfeiçoada e moderada pela razão ${ }^{15}$. Em Hobbes o desejo também segue uma opinião, mas o princípio do benefício próprio somado à instabilidade do prazer (que ora se localiza em um objeto, ora em outro) faz com que os homens prefiram os benefícios imediatos às conquistas duradouras. A lógica de resultados aliada a essa ansiedade por satisfazer o desejo que agora se impõe frustram o projeto da educação para a virtude. Portanto, resta ao soberano a tarefa de conduzir externamente os desejos dos súditos na direção do cumprimento do pacto. Não se trata de educar homens para que passem a desejar conforme a razão, mas sim de fazer com que, pela ameaça de punição e pela promessa de recompensa, eles não desejem descumprir o pacto. Uma vez que os desejos são uma reação ao objeto externo e se configuram na medida em que sentimos ou imaginamos benefícios ou prejuízos, torna-se possível dirigi-los mediante promessas de recompensas e ameaças de prejuízo ${ }^{16}$. Feito o pacto e constituída a sociedade civil, a punição e a recompensa podem, pois, fazer com que os desejos estejam de acordo com os teoremas racionais relativos à paz e à defesa. Mas não é a razão que os forma e determina, e sim as ameaças de punição e as promessas de recompensa, que vêm de fora: se estas fazem com que uma ação pareça mais ou menos proveitosa, os homens identificam no cumprimento da lei um benefício e no descumprimento da lei um dano. No Leviatãa a força e a retórica aparecem, então, como dois instrumentos eficazes e imprescindíveis para dirigir os desejos no sentido da paz e da obediência às regras civis isto é, das virtudes morais. Ambas podem atuar sobre as opiniões de benefício e prejuízo, tornando

\footnotetext{
${ }^{14}$ Cf. Elements of Law I, XII, 2, onde Hobbes diz que o medo é expectativa do futuro e Leviatã, VI, onde o medo é definido como uma opinião de dano proveniente do objeto. A tradução brasileira peca ao traduzir “opinion” por “crença” ao invés de "opinião”.

${ }^{15}$ Sigo aqui a análise de Marco Zingano em "Emoção, ação e felicidade em Aristóteles” Como mostra autor, "já que as emoções se formam a partir de uma cognição, por isso mesmo elas não são refratárias à razão; ao contrário, podem escutar a razão e, deste modo, aperfeiçoar-se, tornando-se assim emoções moderadas” (p. 154).

16 “Também é evidente que todas as ações voluntárias têm origem na vontade, e dela necessariamente dependem; e que a vontade de fazer ou deixar de fazer qualquer coisa depende da opinião de cada um sobre o bem e o mal, e sobre a recompensa ou o castigo que se vão seguir à ação ou à sua omissão" (Do Cidadão VI, 11).
} 
Journal of Ancient Philosophy Vol. II 2008 Issue 2

os homens mais propensos ao cumprimento das leis e mais avessos à desobediência civil $^{17}$. A educação para a virtude é substituída, então, por um projeto de doutrinação, que não visa senão o controle das opiniões com vistas à obediência.

\section{Conclusão}

Procurei mostrar que tanto a substituição do zoon politikon aristotélico pelo princípio do benefício próprio quanto a substituição da eudaimonia pela satisfação individual são etapas fundamentais do argumento que culmina com a prova da necessidade da soberania absoluta. O Estado deve ser da dimensão do leviatã para suprir uma carência moral natural. A necessidade da soberania absoluta, em Hobbes, é derivada, em última instância, de uma característica da natureza humana: a precariedade natural do diálogo entre desejo e razão. Entre as duas faculdades não há diálogo, mas sim uma relação clara de autoridade na qual o desejo se impõe e a razão o serve. Como não se verifica o retorno (ou se verifica muito precariamente) da ação da razão sobre o desejo, a relação é marcada sempre pelo senhorio deste último que, por sua vez, fica à mercê das preferências individuais, múltiplas e inconstantes. A razão, destronada, é incapaz de dar a medida do bem e do mal. Portanto, o comando deverá vir de fora, do leviatã e, para justificá-lo, Hobbes precisa recusar a possibilidade de que o desejo venha a ser aperfeiçoado pela razão e que o sujeito venha a encontrar internamente a boa medida, a chave da boa conduta. A primeira parte das suas obras políticas - dedicadas à filosofia moral - está voltada para provar essa impossibilidade. Privando o sujeito dessa interioridade, Hobbes demonstra a necessidade da soberania absoluta, que oferece externamente a voz de comando que conforma as opiniões e a ação.

\footnotetext{
${ }^{17}$ No Leviatã, Hobbes admite a retórica como um instrumento eficaz para manter a obediência civil. Uma vez que as ações decorrem das opiniões que temos acerca dos benefícios e dos prejuízos que elas podem nos trazer, o bom governo das ações requer o bom governo das opiniões na direção da paz e da concórdia (Leviatã XVIII, p. 109).
} 
Journal of Ancient Philosophy Vol. II 2008 Issue 2

\section{BIBLIOGRAFIA}

ARISTÓTELES. Ethica Nicomachea I 13 - III 8. Tratado da virtude moral. Tradução, notas e comentários de Marco Zingano. São Paulo, Ed. Odysseus. 2008.

HOBBES, T. De Homine. Traduction et commentaire par Paul-Marie Maurin. Paris. Libraire Scientifique et Technique Albert Blanchard, 1974.

HOBBES, T. Leviathan. Edited by R. Tuck. Cambridge, University Press, 1991.

HOBBES, T. Human Nature and De Corpore Politico. Edited by J. C. A. Gaskin. Oxford, University Press, 1994.

HOBBES, T. On The Citizen. Edited and. transl. by R. Tuck and M. Silverthone. Cambridge University Press, 1998.

HOBBES, T. De Corpore. Edition critique, notes, appendices et index par K. Schumann. Paris, Vrin, 1999.

FRATESCHI. Y. A Física da Política: Hobbes contra Aristóteles. Tese de doutorado. FFLCH, USP. 2003.

FRATESCHI. Y. "Filosofia da Natureza e Filosofia Moral em Hobbes” in Cadernos de História e Filosofia da Ciência, série 3, v. 15, n. 1, 2005.

FRATESCHI. Y. “Liberdade e livre-arbítrio em Hobbes”, Cadernos de História e Filosofia da Ciência, Campinas, Série 3, vol. 17, 2007.

LOPES, M. A Relação entre virtude moral e phronêsis no livro VI da Ética Nicomaquéia. Dissertação de Mestrado, FFLCH, USP, 2000

TAYLOR. A. E., “The Ethical Doctrine of Hobbes”, in K. C. Brown (ed.), in Hobbes Studies, Cambridge, Mass., Harvard University Press, 1965.

ZINGANO, M. “Emoção, ação e felicidade em Aristóteles” in Estudos de Ética Antiga. São Paulo, Discurso Editorial, 2007. 